\title{
From Traditional Business toward Social Business: A Single Window E-Platform for the Albanian Port Community System
}

\author{
Alma Stana \\ PhD Candidate, "Aleksander Moisiu" University of Durres \\ stana_alma@yahoo.it \\ Elvin Meka \\ Head of Department of Finance, European University of Tirana \\ elvin.meka@uet.edu.al \\ Prof. Dr. Kozeta Sevrani \\ Head of Mathematics, Statistics \& Applied Informatics Department \\ kozetasevrani@unitir.edu.al \\ Dr. Indrit Baholli \\ Head of Department of Computer Sciences, European University of Tirana \\ indrit.baholli@uet.edu.al
}

\section{Doi:10.5901/ajis.2013.v2n2p191}

\section{Abstract}

\begin{abstract}
The port process and computerization assessments completed for the ports of northern Adriatic, have shown the global importance of computerizing the processes implemented in the maritime-port-logistics cluster, and the absolute need to improve the level of automation in relationships between port operators and in the management of the document flows involved in these relationships. The assessments have shown what benefits could be within the port and over extended communications and data exchange network between the other ports from the implementation of an e-Platform for electronic data interchange capable of establishing communications between the various port computer systems in order to achieve coordination and integration and to promote the concept of "Single Window" with the aim of reducing transaction costs and operation turnaround time.In this paper is given the idea of implementing of e-Platform in the biggest Albanian port of Durres interconnecting the port information systems dedicated to the management of logistic processes and the benefits of it such as development of an accurate and upto-date port organization, port infrastructure and processes analysis among the ports of northern Adriatic and development of a joint market. The implementation of an e-Platform, which is the main objective of the ITS Adriatic multi-port gateway project, represents the ideal way to satisfy the needs for data interchange, communication and integration between the systems identified in the various assessments and for Albanian ports.
\end{abstract}

Keywords: e-Platform, Information Systems, Albanian ports community system.

\section{Introduction}

Marine Ports are the gateways in the international trade driving the economic growth of a country. Any type of port can be seen as the cargo interface between a country and the trade partners with whom the country does business, and this in any phase of the economic growth of a country or region.

In the strategy of European transport, maritime traffic has an important role in the national economy, thanks its low cost and relatively low impact on the environment.

NAPA was established in Trieste in March 2010 by the port authorities of Ravenna, Venice, Trieste and Luka Koper to start mutual cooperation to increase the potential, the quality and the efficiency of the Northern Adriatic ports, transport infrastructures and related services with the general goal to become a European multi-port gateway. 
The port process and computerization assessments completed for the individual ports of NAPA, and the summary and comparison of results included in the overall assessment of the NAPA ports, have shown the global importance of computerizing the processes implemented in the maritime-port-logistics cluster, and the absolute need to improve the level of automation in relationships between port operators and in the management of the document flows involved in these relationships.

The said assessments have also shown what benefits could be obtained locally (i.e. within each individual port) and over the extended "intra- NAPA" communications and data exchange network from the implementation of an IT tool for electronic data interchange capable of establishing communications between the various port computer systems, and in particular between existing port community systems (PCSs), using Electronic Data Interchange (EDI) technology integrated with the various local IT systems.

Such a tool would simplify, standardize, accelerate and render more efficient all port processes requiring interaction between operators in different port communities or between port communities and the local, national and international institutions responsible for authorizing, monitoring, controlling and verifying port processes and the data generated and exchanged.

The implementation of an EDI Platform, which is the main objective of the ITS Adriatic multi-port gateway project, represents the ideal way to satisfy the needs for data interchange, communication and integration between the systems identified in the various assessments. The said platform must, however, offer a high level of flexibility in the management of processes and information (documents and data in general), and its implementation must be based on a thorough analysis of user and system requirements, and on carefully selected document interchange standards.

In particular, these standards must meet the typical operational needs of the individual port communities while simultaneously satisfying the requirements of legislation governing the processes involved.

The EDI Platform must interconnect the NAPA port information systems dedicated to the management of logistic processes, convert the documents generated and processed by these systems into standard EDI messages, and also convert EDI format data into documents capable of being processed by the said information systems.

The platform must therefore dialogue with all the information systems already existing within the individual ports (e.g. port community systems) and with all systems developed during the course of the project's Activity 3 in order to improve the level of computerization using EDI technologies. It must also remain open to communication with third party systems and/or services, including those applications already used by operators within the individual port communities to manage their operations and administer their businesses, and also including institutional information systems such as national and/or international single windows for particular processes (such as the information systems of the coast guards, customs, health inspectorate, etc.).

Main objectives are:

- to improve the existing North Adriatic port community systems;

- to optimize the use of port infrastructures;

- to enhance efficiency and productivity of NAPA ports activities;

- to foster a better inter-modal competitiveness and a more balanced modal distribution;

- to provide an up-to-date and complete port operation application;

- to develop and share "best practices" approach among the Northern Adriatic ports;

- to reduce administrative costs of document handling and communication;

- to reduce time required by the cargo to cross a port node;

- to integrate in one network all ports enabling the entire NAPA community to exchange information;

- to implement a common application based on electronic exchange of data and common web portal for sharing of data;

- to provide a complete information interoperability in a large region at the crossing of Corridors 1 and 5 and extended to the Adriatic-Baltic corridor;

- to maximize client's satisfaction offering the most adequate tool for monitoring and tracking "business" within the Northern Adriatic ports;

- to improve efficiency, safety, security and services of the Northern Adriatic sea transport;

- to provide a complete set of functions to support ship arrival and departure operations; 
- to develop and demonstrate solutions and systems that ensure acceptance and participation by a "wide perspective" of actors involved in transport operations.

In this paper is given the idea of implementing of e-Platform in the biggest Albanian port of Durres interconnecting the port information systems dedicated to the management of logistic processes and the benefits of it such as development of an accurate and up-to-date port organization, port infrastructure and processes analysis among the ports of northern Adriatic and development of a joint market.

\section{Methodology:}

We are going to study the current situation of shipping information management on the ports of Albania, because they have a very important role in regarding security, maintenance and surveillance of marine life. The objects of this study are Information Systems to support reshaping of the port e-platforms role and their impact to a solution of green, global, sustainable and safe for Albanian ports that are far from managing a modern European port.

From a technical point of view, the study will focus on the main ports of Albania consists in the following main activities:

\subsection{Analysis activities:}

- development of an accurate analysis about organization and processes of the NAPA ports,

- assessment of the existing ICT systems at the NAPA ports,

- identification of the requirements of a common e-platform for data interchange,

- definition of the standards to be used for data interchange and sharing;

\subsection{Development activities:}

- improvement of the existing Port Community Systems at the NAPA ports (ICT infrastructural interventions and harmonization of ICT systems),

- setting up an Electronic Data Interchange (EDI) application for integration and data sharing,

- implementation of an e-platform prototype, consisting in a webportal of the NAPA ports, integrated with the enhanced NAPA ports PCS and the EDI application.

During the study will be raised three hypotheses:

H1-Albania can't implement an e-Platform in the Albanian ports.

H2-Albania has an e-Platform in the biggest Albanian port of Durres.

H3-Albania will implement an e-Platform in the biggest Albanian ports interconnecting the port information systems dedicated to the management of logistic processes.

The results of the study will be based on the observation of Albanian ports performance supporting by IT.

This paper will conclude with recommendations regarding the idea of implementing of e-Platform in the biggest Albanian port of Durres interconnecting the port information systems dedicated to the management of logistic processes and the benefits of it such as development of an accurate and up-to-date port organization, port infrastructure and processes analysis among the ports of northern Adriatic and development of a joint market.

\section{Research Literature - (e-Platform)}

E-commerce and multi channel retailing are sectors that rely on technology to provide the route to market and mechanics of merchandising and selling products. Selecting the right technology platform for the business is therefore of paramount importance, much the same way as selecting the right retail premises is of paramount importance in 'bricks and mortar' retailing. Unfortunately, identifying the best technology involves navigating a crowded market with options ranging from free software as a service (SaaS) platforms, through to multi million pound bespoke builds.

\subsection{E-platform concept}

The port process and computerization assessments completed for the individual ports of Ravenna, Venice, Trieste and 
Koper, and the summary and comparison of results included in the overall assessment of the NAPA ports, have shown the global importance of computerizing the processes implemented in the maritime-port-logistics cluster, and the absolute need to improve the level of automation in relationships between port operators and in the management of the document flows involved in these relationships.

The said assessments have also shown what benefits could be obtained locally (i.e. within each individual port) and over the extended "intraNAPA" communications and data exchange network (i.e. the network between the various NAPA ports) from the implementation of an IT tool for electronic data interchange capable of establishing communications between the various port computer systems, and in particular between existing port community systems (PCSs), using Electronic Data Interchange (EDI) technology integrated with the various local IT systems. Such a tool would simplify, standardize, accelerate and render more efficient all port processes requiring interaction between operators in different port communities or between port communities and the local, national and international institutions responsible for authorizing, monitoring, controlling and verifying port processes and the data generated and exchanged.

The implementation of an EDI Platform, which is the main objective of the ITS Adriatic multi-port gateway project, represents the ideal way to satisfy the needs for data interchange, communication and integration between the systems identified in the various assessments.

The platform however must offer a high level of flexibility in the management of processes and information (documents and data in general), and its implementation must be based on a thorough analysis of user and system requirements, and on carefully selected document interchange standards, which must meet the typical operational needs of the individual port communities while simultaneously satisfying the requirements of legislation governing the processes involved.

The EDI Platform must interconnect the NAPA port information systems dedicated to the management of logistic processes, convert the documents generated and processed by these systems into standard EDI messages, and also convert EDI format data into documents capable of being processed by the said information systems. The platform must therefore dialogue with all the information systems already existing within the individual ports (e.g. port community systems). It must also remain open to communication with third party systems and/or services, including those applications already used by operators within the individual port communities to manage their operations and administer their businesses, and also including institutional information systems such as national and/or international single windows for particular processes (such as the information systems of the coast guards, customs, health inspectorate, etc.).

\subsection{The e-platform role}

The e-platform will be used to provide a communication channel among the NAPA ports and between NAPA ports and the so-called "NAPA customers". We intend as "NAPA customers" the operators not localized in NAPA ports but having an interest in sending or receiving data or information related to single ship voyages or general statistics regarding NAPA traffic and trends. They will access e-platform services by the use of the NAPA portal (WP 5). They may be Shipping Lines, forwarders operating in other ports or generic site visitors. In the project context the common e-platform, therefore, plays a double role:

- Providing a structured communication channel among the NAPA ports to better manage intra NAPA traffic, exchanging information useful to activate identified port processes in an automatic way; as a side effect, the same information pieces and protocol will be available to "NAPA customers" to prepare vessel and related goods arrive and departure to/from NAPA area;

- Defining a communication protocol reserved to NAPA ports to provide information useful to build a whole NAPA traffic view (statistics, berthing plan, etc.) to publish through the NAPA portal.

- The e-platform has the scope to provide to NAPA customers or NAPA potential customers an image of unique port with berthing power distributed in each NAPA port (just a Multiport) both from an operational point of view (the first role) and a commercial (or marketing) point of view (the second role).

The objective is to progressively implement, even after the end of the ITS Adriatic Multiport Gateway project, a system able to propose itself outside as a Regional Single Window system (a single window system for north Adriatic area) close collaborating with local PCSs playing the role of local Single Window system for local processes coordination and execution. In this way NAPA customers will be able to interface NAPA ports independently from process differences induced by local legislation, organization or consolidated practices. 


\subsection{Data to exchange through platforms}

In the previous chapters some processes of the various ports to be connected through the services of the target platform have been identified. The outlined data streams have a dual purpose:

- being an operational support to port processes,

- being sources of data to distribute general traffic information about NAPA network through NAPA portal services so promoting the NAPA Multiport concept.

To enhance the second purpose a new process independent data stream is added to make available a global NAPA network traffic statistic. The idea is to collect ESPO statistics of each NAPA port and build up a NAPA network ESPO statistic to show through the NAPA portal traffic quantity and trends.

In the following, the identified data streams are better described: a more detailed description and format definition will be a task of next project stages:

- Statistics

- Information about the arrival of vessels

- Information about container traffic

- Information about berthing plan

- Customs Manifests

- Crew List and Passenger List

- Information about Dangerous Goods

- Ship Certificates

\subsection{E-Platform - Software Requirements}

Requirements identification and definition of standards for the improvement of the electronic data interchange within the NAPA ports and for the implementation of a NAPA common EDI-Platform.

In line with the project definition and the subsequently completed assessments, the e-platform is understood to consist of the following elements:

- local developments of the information systems of the individual ports, aimed at improving

- the computerization of port processes on the basis of Electronic Data Interchange;

- the EDI Platform, the core of the system, understood as the IT tool dedicated to the electronic interchange of data for the purpose of establishing communication between the information systems of the individual ports (or port community systems if these already exist or are planned) and between these and the outside world;

- the Web Portal for the NAPA area, understood as the portal for the services offered by all NAPA ports and closely interlinked with the EDI Platform, from which it obtains some of the information it presents.

\section{Current Situation of Maritime Traffic Management by (Albanian case)}

Actually, in Albania, the monitoring, management and control of maritime traffic within ports and anchorage roads is carried out from Harbour Master Offices at the main Ports along the coast of Albania, Durrës, Vlorë, Shëngjin, Saranda..

Meanwhile coastal monitoring of vessel traffic is covered by Maritime Operational Inter-institutional Center based near Durrës and having its sensors along the coast of Albania. The Center is an Integrated System for the Surveillance of the Albanian Maritime Area which acts as/on behalf of national competent authorities.

The offices of Harbour Masters HMO, for the monitoring of areas of jurisdiction have installed equipments such are: VHF, Radars, AIS, Navtex, etc which are not operating in the framework of an integrated system recommended from IALA standards ${ }^{1}$ for the establishment of the Vessel Traffic Services VTS centers. The personnel mainly of navigators with previous sea service, is not trained for a VTS operation.

${ }^{1}$ IALA - International Association of Marine Aids to Navigation and Lighthouse Authorities 
Such a monitor, restricted to their area of port and anchorage is done through the existing navigational equipment and aids already installed at their premises and offices. The HMO premises of Durrës, Sarandë and Shëngjin have good views on their port and anchorage road areas while the HMO Vlorë, is located in the first floor of a two floored building with very restricted view to port activities and no view on anchorage road. For exercising the activities of VTS center at Port of Vlorë, a new building with good view will have to be considered.

In the port areas, other Port authorities exercise their activities entitled by law like Border Police, Customs, AntiSmuggling Units, Sanitary Inspectorate, Port Directorates, etc.

In their activities, these authorities with sea traffic interests, collect process and store the information of maritime traffic for their operational and statistical purpose, based on their institutional legal framework. They are in close contact with Harbour Master Office for the coordination of their activities with regard to vessels to call at the ports or already alongside.

In this context the Consultants could not trace any regulation or other legal instrument that would facilitate coordination of activities among the Authorities operating in the port area for the management / monitoring of maritime traffic. Such coordination of activities is done on a traditional base cooperation.

Despite the evidential lacks on regulations, any additional / proper equipment and systematic management (storing \& exchange) of information, the situation is the starting point for the establishment of VTS (Vessel Traffic Services) for such ports, aiming the single window services VTMIS (Vessel Traffic Monitoring and Information System).

Other allied services like shipping agents, pilots, forwarders, tug boats, supply, and reception facilities, are important actors for exchange of information on vessel traffic monitoring and information system. Actually, from Durrës Port Authority there are initiates to provide single window system through introducing of integrated pre-arrival information in electronic format, for ships to call the port. Such initiates needs be agreed by other port stakeholders be integrated later on the VTMIS.

The centre is an Integrated System for the Surveillance of the Albanian Maritime Area which acts as/on behalf of national competent authorities, aiming to assure a better organization, planning and commanding of maritime operations, in accordance the international and national maritime legislation providing so interrelation among governmental entities having responsibilities and interests in maritime area management.

Recently approved the Law on the Search and Rescue Service the Albanian Coast Guard is acting as a Maritime Search and Rescue Coordinator through the Maritime Operational Inter-institutional Center MOIC - QNOD as part of National Search and Rescue Center.

The MOIC, as newly established, will have to be equipped with the navigational communication aids and identification codes in accordance with ITU and AKEP regulations as for the GMDSS operational requirements in transmitting and receiving at international band frequencies used by shipping in order to have access at satellite communications of shipping for communication and distress purposes.

From the these analyses we studied the current situation of shipping information management on the ports of Albania, because they are far from managing a modern European port.

The objects of this study were Information Systems to support reshaping of the port e-platforms role and their impact to a solution of green, global, sustainable and safe for Albanian ports that have a very important role in regarding security, maintenance and surveillance of marine life.

The objective is to progressively implement in the Albanian port area, inside of the ITS Adriatic Multiport Gateway project, a system able to propose itself outside as a Regional Single Window system (a single window system for north Adriatic area) close collaborating with local PCSs playing the role of local Single Window system for local processes coordination and execution. In this way Albanian ports consumers like NAPA customers will be able to interface NAPA ports independently from process differences induced by local legislation, organization or consolidated practices.

This paper will conclude with recommendations regarding the idea of implementing of e-Platform in the biggest Albanian port of Durres interconnecting the port information systems dedicated to the management of logistic processes and the benefits of it such as development of an accurate and up-to-date port organization, port infrastructure and processes analysis among the ports of northern Adriatic and development of a joint market.

\section{Conclusions and Recomandations}

In this paper is given the idea of implementing of e-Platform in the biggest Albanian port of Durres interconnecting the port information systems dedicated to the management of logistic processes and the benefits of it such as development 
of an accurate and up-to-date port organization, port infrastructure and processes analysis among the ports of northern Adriatic and development of a joint market.

The results of the study are based on the observation of Albanian ports performance supporting by IT.

The implementation of an e-Platform, which is the main objective of the ITS Adriatic multi-port gateway project, represents the ideal way to satisfy the needs for data interchange, communication and integration between the systems identified in the various assessments and for Albanian ports.

\subsection{The Benefits Of Implementation An Integrated Business Intelligence Platform For The Albanian Port Community System}

Move beyond traditional business intelligence by meeting all of the strategic requirements on a single platform, from traditional business toward social business, providing a full spectrum of ranging from reporting, query and analysis, and dashboards and visualization, to intuitive discovery and advanced predictive analytics capabilities.

At the core of any Business Intelligence solution, a flexible and scalable platform is required in order to discover and share insight for optimal decision-making. An extensive set of tools on a single platform allows IT departments to extend $\mathrm{BI}$ to any application or process in any environment and enables IT to be proactive and actively participate in necessary changes to the overall business. The Business Objects BI platform provides an enterprise-wide information infrastructure that allows the organization to make every person, process, and decision more intelligent - and it closes the loop between information and action.

Benefits of a BI Platform Solution will be:

- Enable IT to be proactive and participate to business changes by delivering the most extensive set of BI tools on a single platform.

- Extend insight from BI to everyone-inside and outside the organization-by taking advantage of a flexible, and scalable service-oriented architecture with extensibility, so you can add new services without requiring a release of the entire platform.

- Multi-server support, fault-tolerance, and intelligent load balancing ensure you can extend information to all users when and how they need it. The BI platform also delivers multi-level caching, cross-platform support, and comprehensive system administration, management, and security.

\subsection{Query, Reporting and Analysis}

Easy-to-use query, reporting and analysis tools illuminate business information inside and outside the organization by providing access to the most requested items of information reliably and securely. Enlighten the organization's performance by accessing the data and transforming it into actionable information with interactive reports. End users can interact with business information and answer ad hoc questions themselves without having to understand complex database languages and underlying structures. Query, reporting and analysis serve as the starting point solution set for a broad based BI strategy.

An Integrated BI Platform will:

- Transform data into actionable information with a powerful reporting solution that helps you design, explore, visualize, and deliver reports via the web or embedded in enterprise applications.

- Allow end users to consume reports with visualization techniques, conduct on-report business modeling, and execute decisions instantly from the report itself reducing dependency on IT and developers.

- Query and analysis tools enable the users to identify trends and find root causes in data from relational and OLAP data sources. A range of users from experienced analysts to mainstream business users can easily create queries and perform calculations without understanding complex database schemas or SQL.

- Our reporting, query and analysis solutions are built on our proven, mature BI platform ensuring the deployment meets performance demands and supports standardization efforts.

\subsection{Information Delivery}

Provide the business with consolidated views of key metrics and information and dynamically explore relationships, 
trends and timelines. Display the BI content together in one unified view, and users are empowered to make the right decisions and improve overall business performance. Through "what-if" analysis, customer segmentation and forecasting, you can transform information and interact with sophisticated visual representations of business processes that provide new insights and the ability to respond quickly with informed decisions. The Business Objects BI platform integrates market-leading data mining and predictive analytic capabilities, which help individuals in the company to explore past and present business scenarios, as well as uncover trends and identify outliers to project future outcomes.

An Integrated BI Platform will bring these other benefits:

- Leveraging universe security, users only access what they are privileged to see and they can navigate from a high-level summary to detailed analysis.

- With drag-and-drop functionality, organizations can quickly build dashboards and rapidly deploy them across the organization.

- Stay up-to-date with access to BI information from any wireless device and take immediate action by interacting with reports, metrics, and real-time data.

- Easily embed and update new data in the Microsoft Office Word documents, Excel spreadsheets and PowerPoint presentations and instantly share the documents securely over the web for collaborative decisionmaking.

\subsection{Information Discovery}

Reporting and query and analysis are excellent for business people who have some idea of what they are looking for. But what about users who want to sift and browse through data in the same way they are used to browsing through information sources like the Web? A new category of tools call information discovery covers this need. Rather than just searching documents, our information discovery tools allow people to browse through data in an easy and intuitive way. Locate information hidden in hundreds of internal and external resources, such as structured databases, business intelligence $(\mathrm{BI})$ systems, unstructured company and text content, search engines and the web.

The installation of an Integrated BI Platform will be:

- Take advantage of integrated text analysis and search capabilities, enabling the organization to combine and complement quantitative information from structured sources with qualitative insight from unstructured sources.

- Powerful extraction, categorization, and summarization capabilities allow the decision-makers to quickly identify and understand the concepts, people, organizations, places, and other information that only exists in unstructured text sources.

- Quickly search, locate and highlight business intelligence (BI) content from Google Search Appliance and other search engines favored by employees to increase productivity by finding BI reports and metrics alongside related business documents and web pages while full BusinessObjects security is applied and maintained.

\subsection{Enterprise Information Management}

Data management practices and technology form the core of all business initiatives. Without complete and accurate customer, product, and sales information, the business initiative is unsustainable. With Business Objects enterprise information management (EIM) tools as data integration, data quality, and metadata management, can transform questionable data into trusted sources to establish a foundation of data integrity for the business decisions. By profiling, cleansing, and continuously monitoring the data, can ensure that this business data is correct, consistent, and complete.

The results after installation of an Integrated BI Platform will be:

- Data integration allows you to quickly integrate data from multiple enterprise systems to support the development of a data warehouse or departmental data mart.

- Pre-built data marts allow you to accelerate the BI deployment and gain rapid access to data from enterprise applications such as SAP, Oracle, Siebel, and PeopleSoft. 
- Data federation augments data warehousing by offering real-time integration to multiple source systems, quickly and with minimal impact to operational applications themselves.

- Metadata management allows you to quickly track the source of any data element from the report, back to the source, including any calculations or transformations made at any step along the way.

- Data profiling and data quality ensure that you have optimal visibility to assess the quality of the data, correct and consolidate the information, and monitor the data quality improvements over time.

At the end of our study the result is that Albania will implement an e-Platform in the biggest Albanian ports interconnecting the port information systems dedicated to the management of logistic processes and the benefits of it such as development of an accurate and up-to-date port organization, port infrastructure and processes analysis among the ports of northern Adriatic and development of a joint market.

\section{References}

Prof. Jens Froese, "Seaport integration and networking - An European Case study", APAA Seaports magazine 2011

T. Anupama, I Krishna, K. Deepa "Automation in leading container units" 2011.

"Preliminary Assessment \$ Feasibility Design for the establishment of the VTMIS" Louis Berger , 2011

Vaziri "Automated technologies in Maritime Container Terminals

Antonio Grilo, Ricardo Jardim-Goncalves 2005 "Analysis on the development of e-platforms in the AEC sector"

Michael Taylor, Andrew Murphy "SMEs and e-business"

http://www.portsofnapa.com/

http://tentea.ec.europa.eu/

http://www.accelacommunications.com/microsite/biplatform/index.html

2010 TEN-T Programme Motorways of the Sea "ITS Adriatic multi-port gateway" project [Code: 2010-EU-21106-S] EPCSA Committee Meeting -Sofia, 18 July 2012

ITS Adriatic Multi-port gateway "E-Platform - Software Requirements - Specification - Requirements identification and definition of standards for the improvement of the electronic data interchange within the NAPA ports and for the implementation of a NAPA common EDI-Platform

NAPA: "Market study on the potential cargo capacity of the North Adriatic ports system in the container sector" Draft report by MDS Transmodal Limited 2011

ITS Adriatic Multi-port gateway "Overall Assessment Of The Napa Ports" Analysis of the state of the art of organization, processes and ICT systems in the ports of NAPA 
